\title{
Tree Species Diversity and Composition of Miombo Woodlands in South-Central Angola: A Chronosequence of Forest Recovery after Shifting Cultivation
}

\author{
Francisco M. P. Gonçalves, ${ }^{1,2}$ Rasmus Revermann, ${ }^{2}$ Amândio L. Gomes, ${ }^{2,3}$ \\ Marcos P. M. Aidar, ${ }^{4}$ Manfred Finckh, ${ }^{2}$ and Norbert Juergens ${ }^{2}$ \\ ${ }^{1}$ Herbarium of Lubango, ISCED Huíla, Sarmento Rodrigues Str. CP 230, Lubango, Angola \\ ${ }^{2}$ Biocentre Klein Flottbek, University of Hamburg, Ohnhorststr. 18, 22609 Hamburg, Germany \\ ${ }^{3}$ Department of Biology, Faculty of Sciences, Agostinho Neto University, Av. 4 de Fevereiro 71, 4 Andar Luanda, Angola \\ ${ }^{4}$ Plant Physiology and Biochemistry, Institute of Botany, CP 3005, 01061-970, São Paulo, SP, Brazil \\ Correspondence should be addressed to Francisco M. P. Gonçalves; francisco.maiato@gmail.com
}

Received 15 July 2016; Revised 29 November 2016; Accepted 14 December 2016; Published 1 March 2017

Academic Editor: Piermaria Corona

Copyright (C) 2017 Francisco M. P. Gonçalves et al. This is an open access article distributed under the Creative Commons Attribution License, which permits unrestricted use, distribution, and reproduction in any medium, provided the original work is properly cited.

\begin{abstract}
The study was carried out in the Cusseque area of the Municipality of Chitembo in south-central Angola. Our objectives were to assess the floristic diversity, the species composition, and stand structure of Miombo woodlands during regeneration after shifting cultivation. A total of 40 plots of $1000 \mathrm{~m}^{2}$ were surveyed and analyzed, corresponding to mature forests/woodlands and three fallow types of different age. The analyses were based on plot inventories of all trees with $\mathrm{DBH} \geq 5 \mathrm{~cm}$. A total of 51 woody species, 38 genera, and 19 families were recorded. The dominant family was Fabaceae, with subfamily Caesalpinioideae being very abundant. Shannon Diversity and Evenness were highest in mature forests and young fallows, while the mature forest stands showed the highest species richness. A Principal Coordinates Analysis (PCoA) showed many species shared between the intermediate fallow types, but only few species were shared with young fallows. Mature forests formed a clearly distinct group. This study shows potential pathways of forest recovery in terms of faster regeneration after agricultural abandonment and, thus, the results presented here can be used in future conservation and management plans in order to reduce the pressure on mature forests.
\end{abstract}

\section{Introduction}

Forests and woodlands in Africa play an important role in the livelihood of many communities and in the economic development of many countries [1]. Forest ecosystems are important not only for supplying timber and other economically important products (e.g., charcoal), but also for generating indirect benefits such as controlling soil erosion, supporting soil fertility, providing shade, and buffering hydrological cycles [2].

The forest resources in most African countries are threatened by various natural and anthropogenic disturbances, especially overexploitation. Thus, the problem of unsustainable use of forest resources is of increasing concern in these countries, due to the fact that forest losses are causing land degradation and habitat loss for forest taxa [3]. Direct causes of deforestation and land degradation in south-central Africa include land conversion, for example, by expansion of shifting cultivation practiced by small holders and infrastructural or agroindustrial expansion, and overexploitation, for example, for timber, fuelwood, and charcoal [4].

Shifting cultivation is an agricultural system practiced in the tropics for thousands of years, being the main source of subsistence for people in many rural areas [5]. This agricultural practice is characterized by a rotation of fields rather than of crops, by short periods of cropping (one to five years), alternated with long fallow periods (up to twenty or more years, but often as short as six to eight years), and by clearing the fields using slash-and-burn techniques. Fields are normally prepared using a hoe or digging stick, the plow only 
rarely being employed $[6,7]$. The use of fire serves to clear the field and enrich the soil with nutrients from the ash of the woody biomass [8].

This agricultural system has been labeled as the most serious land use problem and a major driver of deforestation in tropical areas of Africa $[9,10]$. It has been, however, an ideal solution for soil fertility in the humid tropics, at least in the past when the human population density was low and fallow periods were long enough to restore soil fertility $[11,12]$. The rapid growth of human population in rural areas of Africa and increasing needs for food production have caused the shortening of fallow periods of abandoned fields and people to encroach into new areas that have not been subjected to agriculture before [12]. The increasing demands of the rapidly growing human population have led to land scarcity, and the remaining forests are being increasingly over utilized, far beyond their capacity for regeneration [13]. This process, as a whole, seriously impacts forest biodiversity patterns, for example, species richness and composition [14].

The Angolan Miombo, which refers to dry tropical forests in south-central Africa dominated by tree species of the genera Brachystegia, Julbernardia, and Isoberlinia [15], are poorly known in terms of woody species diversity, composition, and resilience after abandonment. Data on species diversity and composition are confined to sporadic and outdated studies (e.g., Monteiro, [16]). Almost nothing is known on the dynamics of forest recovery following disturbance, which hampers any systematic management approaches aimed at sustainable use of forest resources. To obtain a holistic view on forest resources of the Angolan Miombo, it is crucial to understand variations in tree species composition, to analyze patterns of species distributions in the forests, and to quantify the relative contribution of different species to overarching patterns [17].

In order to manage disturbed and undisturbed stands and to understand the provision of nontimber ecosystem services, it is imperative to describe patterns of species composition [13]. Additionally, data on woody species composition serve as baseline information for projecting changes in vegetation over time, which is fundamental to understand regeneration processes, such as tree growth, tree mortality, understory development, and the spread of disturbances [18].

The present study was conducted in the Cusseque area of the Municipality of Chitembo, in southern Bié province, which is situated in the center of the Angolan Miombo region. This area is at the current front of deforestation of African dry tropical forests [19]. This study aims to assess the woody species diversity and composition on abandoned agricultural crop fields and mature forest stands in the Cusseque area in order to

(i) analyze changes on woody species composition during forest recovery;

(ii) assess changes of woody species diversity during a slash-and-burn cycle;

(iii) understand the temporal dynamics and timeline of forest regeneration from field abandonment to mature forest.

\section{Material and Methods}

2.1. Study Area. The study area is located on the southern slope of the Angolan Central Plateau in the Bié province $\left(13.6985^{\circ} \mathrm{S}, 17.0382^{\circ} \mathrm{E}\right)$, and it is one of the research sites of the Future Okavango Project in Angola (Figure 1). The mean elevation is $1560 \mathrm{~m}$ with a mean annual temperature of $20.4^{\circ} \mathrm{C}$ $[20,21]$.

The study area has a tropical subhumid climate, with a rainy season of approximately six months lasting from October to April and a dry season corresponding to the remaining period of the year. For the period 1971 to 2000, the mean annual precipitation was $987 \mathrm{~mm} /$ year. However, the annual rainfall in Cusseque shows a high interannual variability with a slightly decreasing trend since the 1970s [21]. During the dry season frosts frequently occur, especially in the valleys [22]. The soils of the study area correspond mainly to ferralitic soils, with a shallow sandy top horizon.

The vegetation of the study site is dominated mainly by typical Miombo woodlands species [23]. Brachystegia spp., Julbernardia paniculata, Cryptosepalum exfoliatum subsp. pseudotaxus, and Erythrophleum africanum are locally dominant tree species [16, 24-28]. The woodlands range from 4 to $15 \mathrm{~m}$ in height, with sparse to moderate grass or shrub layers below the continuous canopy [27]. While undisturbed forests seem to be mostly single stemmed, many stands show signs of earlier slash-and-burn agriculture with multistemmed trees above knee height. Fire also plays an important role in the current forest dynamics [29], especially during the grass dominated early fallow stages.

The human population of the study area mostly belongs to the ethnic group Cokwe. Subsistence agriculture based on shifting cultivation is their main source of livelihood, with maize (Zea mays), cassava (Manihot esculenta), beans (Phaseolus vulgaris), and peanut (Arachis hypogaea) being the main crops. Other sources of income include livestock keeping, wage labour, and, notably in the nearby town of Chitembo, the retail of natural resources like charcoal, bushmeat, and honey [30].

2.2. Site Selection and Data Collection. Forests and fallows were sampled to represent a chronosequence of forest recovery in order to study the state of origin and the dynamics of regrowth. The site selection was done through informal meetings with traditional authorities and the community in general, aiming to identify sites of former slash-andburn agriculture and known age since abandonment. The information obtained regarding the fallows ages was confirmed with remote sensing data, obtained from LandTrendr, a programme that detects disturbance within Landsat timeseries [32].

The selected areas were then grouped into four categories, according to fallow age: young fallows (range 7-8 yrs), medium-aged fallows (range 10-14 yrs), old fallows (range 20$21 \mathrm{yrs}$ ), and mature forests (undisturbed forests or woodlands, showing structural features characteristic of later stages of stand and succession development).

Field work was carried out during March, May, and June 2013 and in September 2014, using $20 \mathrm{~m} \times 50 \mathrm{~m}$ plots, that 

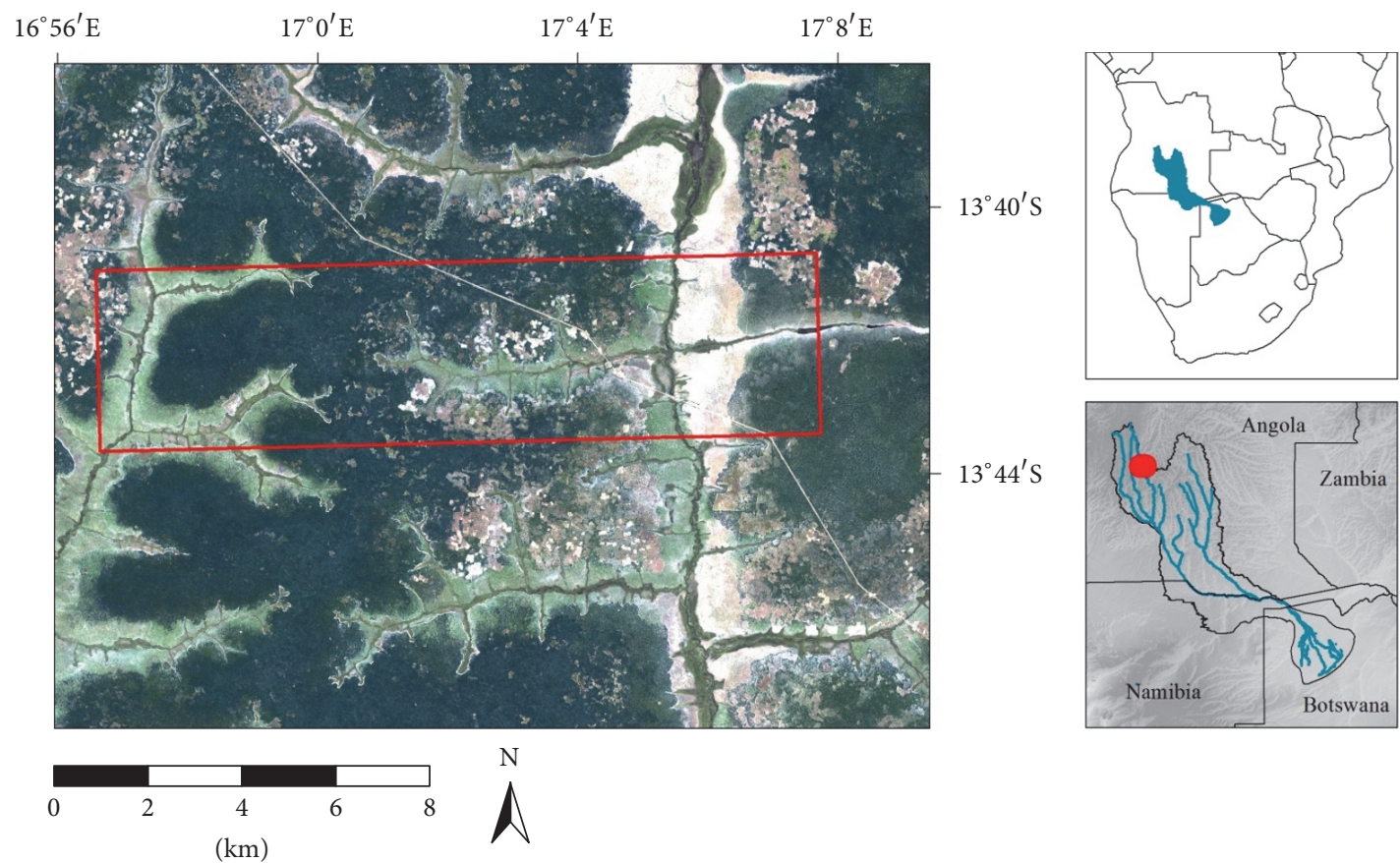

Projection: WGS 1984; background: RapidEye high resolution satellite imagery, recorded May 1, 2013. We acknowledge the DLR for the provision of the data from the RapidEye Science Archive.

FIGURE 1: Location of the Okavango basin in southern Africa and the study site in Cusseque (denoted in red). The Okavango basin as shown here follows the definition of "The Future Okavango Project" http://www.future-okavango.org [31].

were divided into ten $100 \mathrm{~m}^{2}$ subplots [33]. A total of forty plots were surveyed, corresponding to ten mature stands and ten in each of the fallow stages. On every plot we recorded the occurrence of tree species with $\mathrm{DBH} \geq 5 \mathrm{~cm}$. As complementary information, covers of herbaceous and shrub species in a central $100 \mathrm{~m}^{2}$ subplot were also recorded.

If not already known to the authors, the species were identified by their local name in Cokwe (given by local field guides), collected, and taxonomically identified following fieldwork. Voucher specimens are stored at the Herbarium of Lubango (LUBA) and Kew Herbarium (K). The scientific names and authors of the species follow the checklist of Angolan vascular plants [34].

2.3. Data Analysis. Diversity refers to different measures of the species richness and composition. Measures include species richness and evenness [35]. Species richness refers to the total number of species recorded in each forest stage. In this study we also calculated the Shannon Diversity Index [36]:

$$
H^{\prime}=-\sum p_{i} \ln \left(p_{i}\right)
$$

In the Shannon Diversity Index $\left(H^{\prime}\right), p_{i}$ is the number of individuals of species in a given plot divided by the total number of individuals in the plot, ln is the natural logarithm, and $\sum$ is the sum of the calculations. The index incorporates the species richness and the proportion of each species in all sampled plots (evenness) [35, 37]. The evenness in species abundance was assessed by Buzas \& Gibson's Evenness Index [37]:

$$
E=\frac{e^{H}}{S} .
$$

In the Buzas \& Gibson's Evenness Index $(E), H$ is the Shannon Diversity Index, $e$ is the natural logarithm base, and $S$ is the total number of species. Evenness is the equitability of the abundances of different species, and the index varies from 0 to 1 , with 1 indicating that all species have the same abundance $[37,38]$.

To compare the diversity of the four forest stages, we calculated diversity profiles for every stage. Diversity profiles provide a graphical representation of the shape of a community, have the advantage of combining multiple diversity measures (e.g., species richness, Shannon Diversity, and Simpson's diversity) at once, and display one curve per category, in this case fallow stage [39-41].

This allows for a more complete picture of the multidimensional term biodiversity, instead of calculating a few isolated diversity indices only. The scale parameter alpha $(\alpha)$ gives the order of Renyi's diversity, $\alpha=0$ gives the total number of species (species richness), $\alpha=1$ gives the index proportional to the Shannon Diversity Index, and $\alpha=2$ gives an index which behaves like Simpson's index, while $\alpha=\operatorname{Inf}$ refers to the relative abundance of the most abundant species [42].

Stand structure was calculated from stems density in each fallow and mature forest site. A nonparametric test (KruskalWallis) was used to assess differences on stand density 
between fallows and mature forest stands. Population structure was used to assess dynamics in population for the mature stands. Woody species composition was analyzed using the Importance Values Index (see (3)), which is the summation of the relative values of frequency, density, and dominance [43]. The Importance Values Index (IVI) describes the floristic structure and composition of the woodlands and has been frequently used in the Miombo systems [44-46].

$$
\mathrm{IVI}=\frac{(\mathrm{RF}+\mathrm{RD}+\mathrm{RDo})}{3}
$$

where IVI: is Importance Value Index; RF: is relative frequency; RD: is relative density; and RDo: is relative dominance.

The frequency is a statistical parameter which reflects the spread of a species in a given area. The relative frequency (see (4)) of species was obtained from absolute frequency, dividing the number of sampling units $\left(100 \mathrm{~m}^{2}\right.$ subplots $)$ in which the species occurs by the total number of sampling units.

The density of a species reflects the abundance of a species in a given community. The relative density (see (5)) was obtained from absolute density calculated from the total number of individual of a species present in a plot divided by the total area sampled ( $0.1 \mathrm{ha})$.

The dominance is defined as the area occupied by the basal area of a species per plot $(0.1 \mathrm{ha})$. The relative dominance (see (6)) was obtained by dividing the total basal area for a given species by the total basal area of all species per plot. To calculate relative frequency, density, and dominance of the species we used standard formulas [47-49].

$$
\mathrm{RF}=\frac{\mathrm{AF}}{\mathrm{TF}} \times 100,
$$

where RF: is relative frequency of species; AF: is absolute frequency of the species; and TF: is sum of absolute frequencies of all species.

$$
\mathrm{RD}=\frac{\mathrm{AD}}{\mathrm{TD}} \times 100
$$

where RD: is relative density of species; $\mathrm{AD}$ : is absolute density of species (per ha); and TD: is total density of trees (per ha).

$$
\mathrm{RDo}=\frac{\mathrm{ADo}}{\mathrm{TDo}} \times 100
$$

where RDo: is relative dominance of species; ADo: is absolute dominance (or basal area) of species; and TDo: is total dominance (or basal area) of all species.

To explore information on samples and variables (species) we used a Principal Component Analysis biplot [50]. A biplot analysis gives graphical representation of a multivariate sample and it superimpose on the display a representation of the variables on which the sample is measured [51].

Patterns in the species composition of vegetation plots across fallow stages were explored using the Principal Coordinates Analysis (PCoA), based on the original abundance matrix data [50]. The Principal Coordinates Analysis (PCoA) is an eigen-vector-based method which reduces the dimensionality by projecting multidimensional datasets into a smaller number of dimensions [52], allowing a much wider definition of dissimilarity than simple Euclidian distance in the species space, focusing on the associations between individual observation in a dataset $[52,53]$. Calculations of diversity indices, evenness, diversity profiles, Principal Coordinates Analysis (PCoA), and biplot of Principal Components Analysis (PCA) were computed in PAST (Paleontological Statistics Software) (version 2.17).

The overlap of the vegetation composition of the four categories was assessed based on an Analysis of Similarity (Oneway ANOSIM). Values of $R_{\text {ANOSIM }}$ range from 0 to 1 . Values close to 0 indicate strong overlap [53], while values close to 1 indicate complete separation among the groups [54]. To illustrate how many woody species are shared between the four categories, a Venn diagram was drawn with the Bioinformatics \& Evolutionary Genomic Tool (http://bioinformatics.psb .ugent.be/webtools/Venn/).

Additionally, Indicator Species Analysis (ISA) was calculated in the R Statistical Analysis Software [55], to identify the diagnostic species of each fallow stage. Associations of species to more than one fallow stage were allowed $[56,57]$.

\section{Results}

3.1. Woody Species Diversity. The species richness, measured by the total number of tree species recorded, was higher in mature forests (44) and medium-aged fallows (41), being lower in old (36) and young fallows (31). The overall species diversity as measured with the Shannon Diversity Index $\left(H^{\prime}\right)$ was highest in mature forests (2.91), followed by young fallows (2.81) and medium-aged fallows (2.71). The old fallows showed the lowest species diversity (2.61). The highest value of evenness $(E)$ was found in young fallows $(0.53)$, followed by mature forests (0.41) and old fallows (0.37). Medium-aged fallows showed the lowest evenness value (0.36).

The diversity profiles indicate that mature forests were more diverse than medium-aged fallows and old fallows as the graphs of the respective diversity profiles did not intercept, and also they feature higher species richness than young fallows (graph higher for low alpha). Only if evenness (high alpha) is considered, young fallows have higher values than mature forests (Figure 2).

3.2. Stand Structure and Species Composition. We recorded a total of 3.157 individuals: 445 individuals in young fallows, 760 individuals in medium-aged fallows, 965 individuals in old fallows, and 987 individuals in mature forests. The mean stand density in early regrowth fallows was $45 \pm 16$ stems ha $^{-1}$ stems, ranging from 17 to 69 stems ha $^{-1}$. In the mediumaged fallows the mean stand density was $76 \pm 28$ stems ha $^{-1}$, ranging from 35 to 125 stems ha $^{-1}$. Old fallows showed a mean density of $97 \pm 23$ stems ha $^{-1}$, stems ranged from 65 to 140 stems $\mathrm{ha}^{-1}$. While the mature forests mean stand density was $99 \pm 48$ stems ha ${ }^{-1}$, ranging from 45 to 191 stems ha $^{-1}$. Stand density was significantly different between the fallow types and mature forests $(H=16.18 ; p=0.001)$, being 


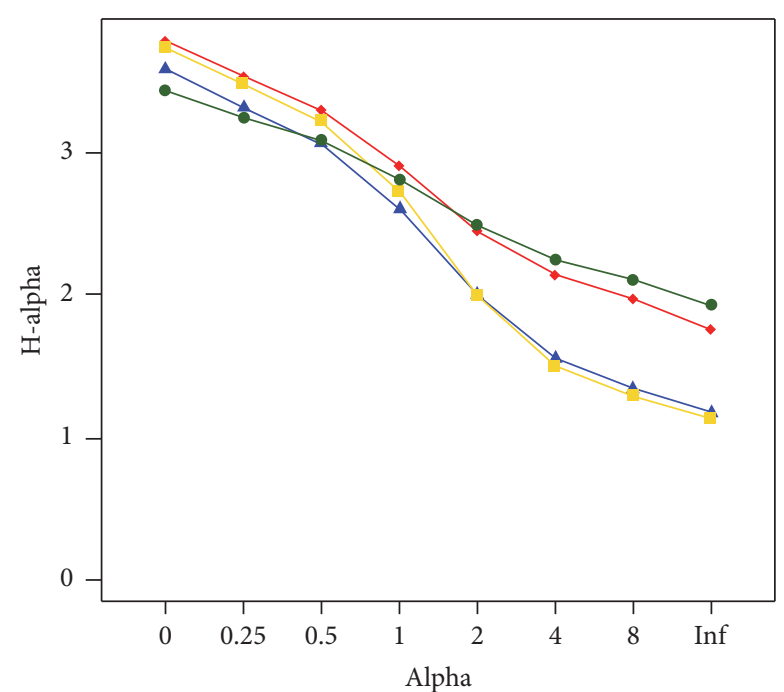

Figure 2: Diversity profiles using Renyi's diversity of three fallows stages and mature forest stands (mature forests: red; old fallows: blue; medium-aged fallows: yellow; and young fallows: green).

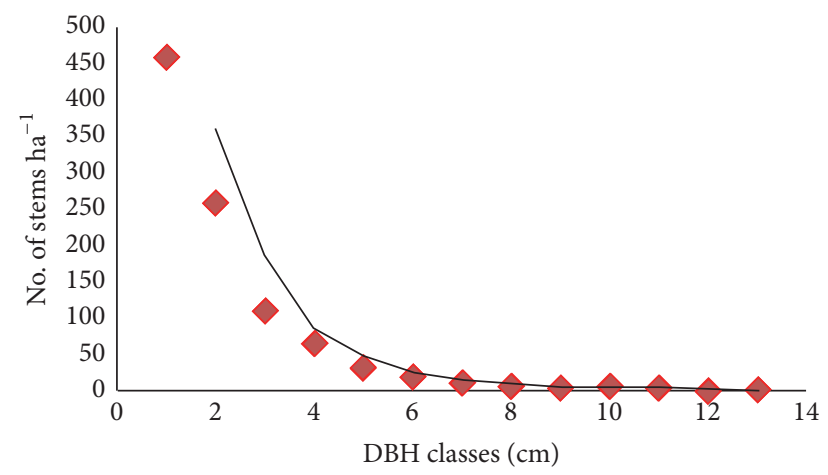

FIGURE 3: Size class distribution of mature forests showing a reverse J shape, the numbers represent the DBH classes in cm. 2 (10-15), 4 (20-25), 6 (30-35), 8 (40-45), 10 (50-55), 12 (60-65), and $14(\geq 65)$.

more evident between early regrowth stages, old fallows, and mature stands. The mean diameter in mature stands was $13.2 \pm 8.8 \mathrm{~cm}$, showing reverse J-shaped size class distribution with the majority of trees found in the smaller diameter classes, accounting for $47 \%$ of stems (Figure 3 ).

These individuals belong to 51 species from 38 genera and 19 families. Two species could not be identified and another two were only identified to genus level (Table 1). The most diverse family was Fabaceae subfamily Caesalpinioideae representing (30\%) of all woody species, followed by Strychnaceae (Loganiaceae) and Combretaceae (9\%), Myrtaceae and Proteaceae (7\%), Euphorbiaceae (6\%), and Apocynaceae, Dipterocarpaceae, Euphorbiaceae, and Melastomataceae (4\%). Rubiaceae and other smaller families represent less than $2 \%$ of species.

The structural analysis of woody species represented by the relative values of frequency, density, dominance, and Importance Values Index (IVI) is summarized in Table 1 in alphabetical order of the species. The dominant species

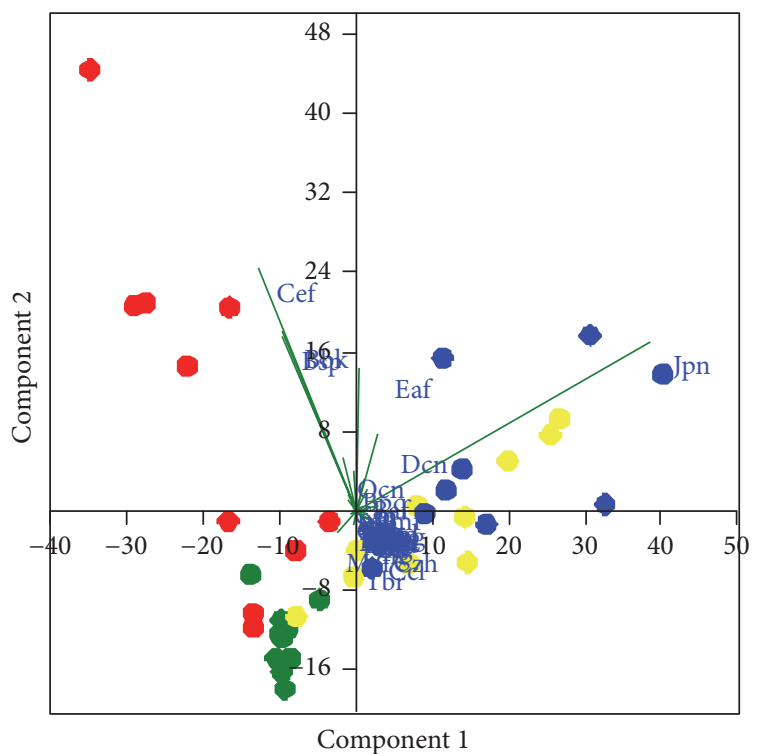

Figure 4: Biplot of the Principal Components Analysis for the variables (species) quantified across the plots, (young fallows: green; medium fallows: yellow; old fallows: blue; and mature forests: red).

ranked by their IVI in all categories were Brachystegia spiciformis, Burkea africana, Combretum collinum, Combretum zeyheri, Cryptosepalum exfoliatum subsp. pseudotaxus, Diplorhynchus condylocarpon, Erythrophleum africanum, Julbernardia paniculata, Monotes africanus, Pericopsis angolensis, and Terminalia brachystemma.

The biplot analysis of PCA explained 60\% (39\% and 21\% for the first and second axis, resp.) of the species variation observed across the fallows and mature forest plots (Figure 4). The early regrowth stages are characterized by the dominance of Albizia spp., Anisophyllea boehmii, Pericopsis angolensis, and Combretum species. Cryptosepalum exfoliatum subsp. pseudotaxus and Brachystegia spiciformis dominated the mature stands, while Erythrophleum africanum, Julbernardia paniculata, and Diplorhynchus condylocarpon characterized the medium-aged stands and old fallows. Strychnos species showed high variation in terms of frequency, density, and dominance in all stages. Two exploitable woody species Guibourtia coleosperma and Pterocarpus angolensis showed few individuals in all fallows stages.

3.3. Principal Coordinates Analysis (PCoA) and Analysis of Similarity (ANOSIM). The Principal Coordinates Analysis of species density and composition distinguished four different groups. The first axis explained $18.4 \%$ of variation (Eigenvalue $=1.9$ ), and the second axis explained $14.8 \%$ of variation (Eigenvalue $=1.5)$. The first group was formed by the young fallows; the second and third groups were formed by medium-aged and old fallows, while the fourth group was formed by the mature forests (Figure 5).

The old and medium fallows showed many shared species, as indicated by Analysis of Similarity $\left(R_{\mathrm{ANOSIM}}=0.052\right)$. Only few species are shared between young and medium fallows $\left(R_{\text {ANOSIM }}=0.487\right)$. The group formed by mature stands 


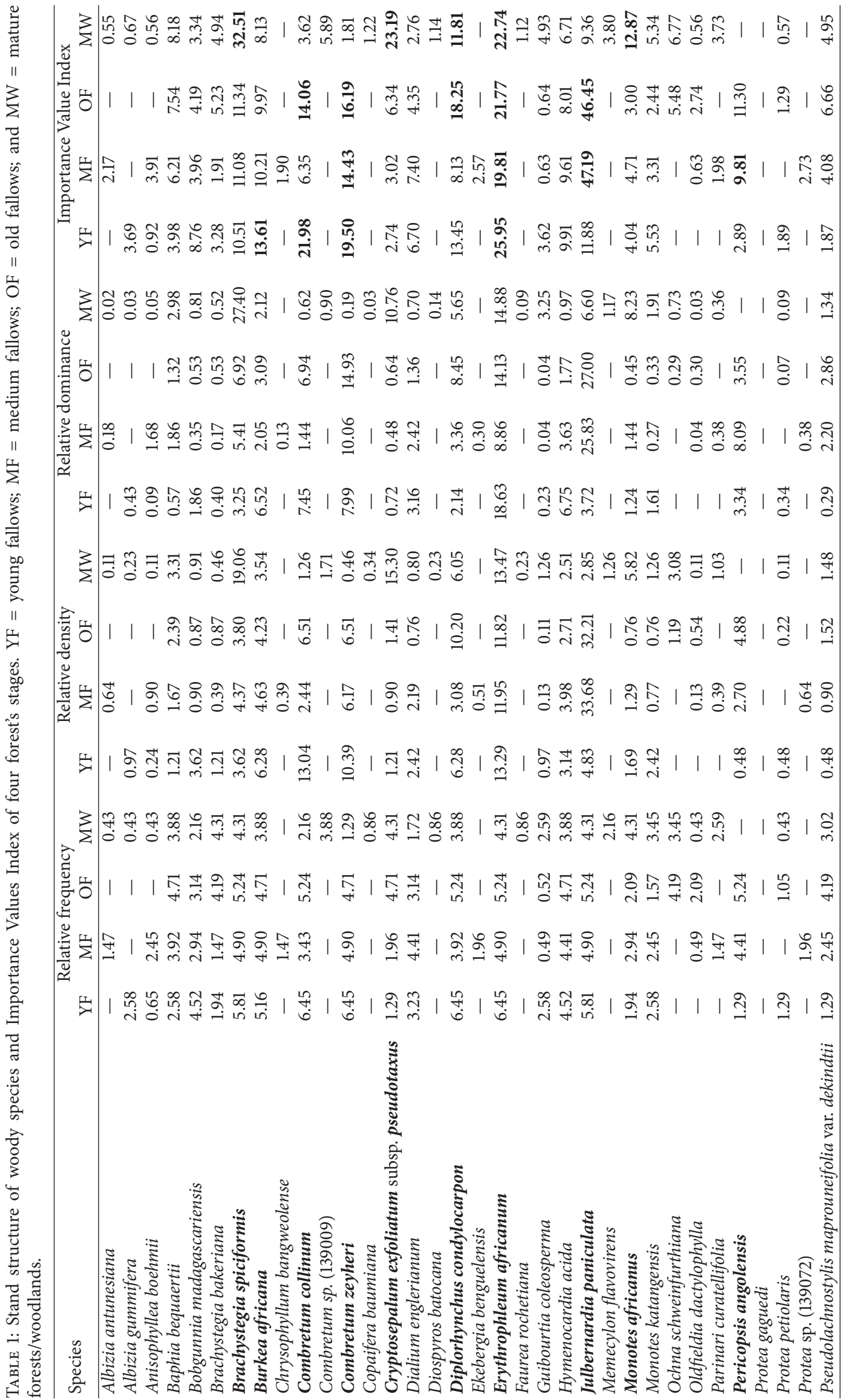




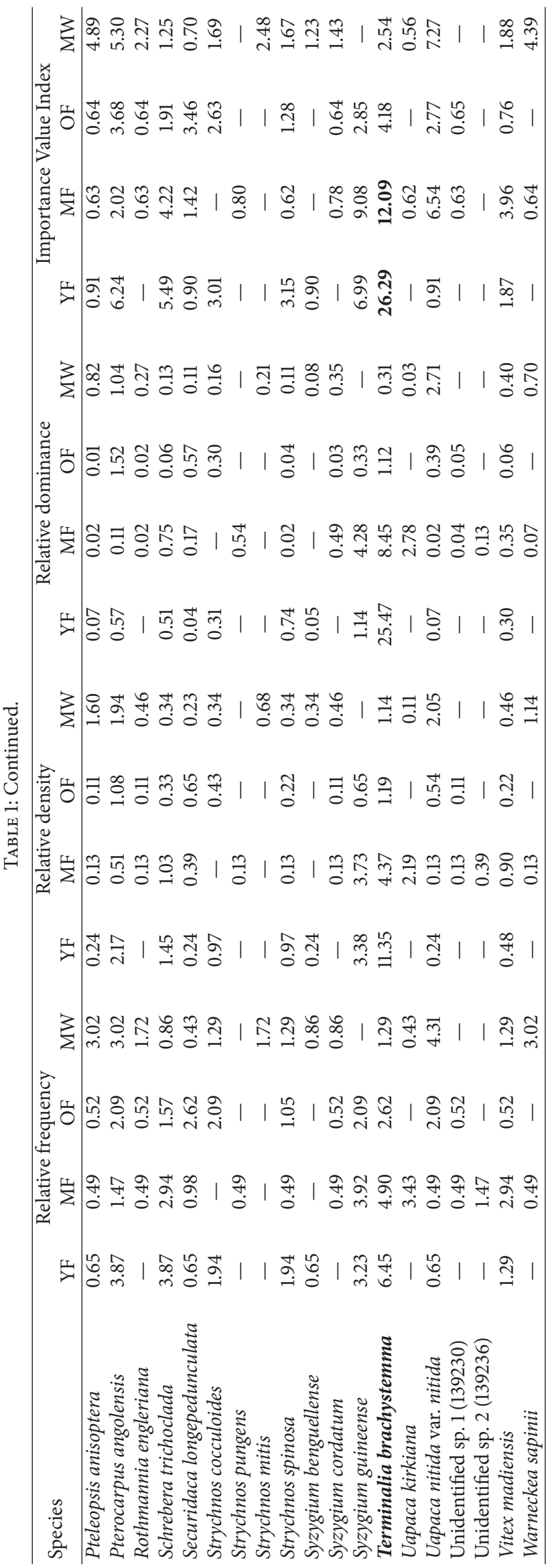


TABLE 2: Indicator species, $p$ values, and significance stars $[*]$ of single and combined groups of fallows stages and mature stands as observed in the Cusseque area.

\begin{tabular}{|c|c|c|c|c|}
\hline Fallow age & Species & Ind. value & $p$ values & Sig. stars \\
\hline Young fallows & Albizia gummifera & 0.516 & 0.036 & $*$ \\
\hline Old fallows & Pericopsis angolensis & 0.808 & 0.001 & $* * *$ \\
\hline Medium \& old fallows & Julbernardia paniculata & 0.971 & 0.001 & $* * *$ \\
\hline Medium fallows \& mature forests & Parinari curatellifolia & 0.632 & 0.03 & * \\
\hline Medium, old fallows \& mature forests & Baphia bequaertii & 0.827 & 0.028 & * \\
\hline \multirow{2}{*}{ Medium, old, \& young fallows } & Combretum collinum & 0.919 & 0.002 & $* *$ \\
\hline & Combretum zeyheri & 0.919 & 0.001 & $* * *$ \\
\hline Old fallows \& mature forests & Ochna schweinfurthiana & 0.765 & 0.002 & $* *$ \\
\hline \multirow{6}{*}{ Mature forests } & Cryptosepalum exfoliatum subsp. pseudotaxus & 0.857 & 0.001 & $* * *$ \\
\hline & Brachystegia bakeriana & 0.796 & 0.002 & $* *$ \\
\hline & Strychnos cf. mitis & 0.707 & 0.002 & $* *$ \\
\hline & Warneckea sapinii & 0.674 & 0.009 & $* *$ \\
\hline & Combretum sp. & 0.632 & 0.005 & $* *$ \\
\hline & Memecylon flavovirens & 0.548 & 0.048 & * \\
\hline
\end{tabular}

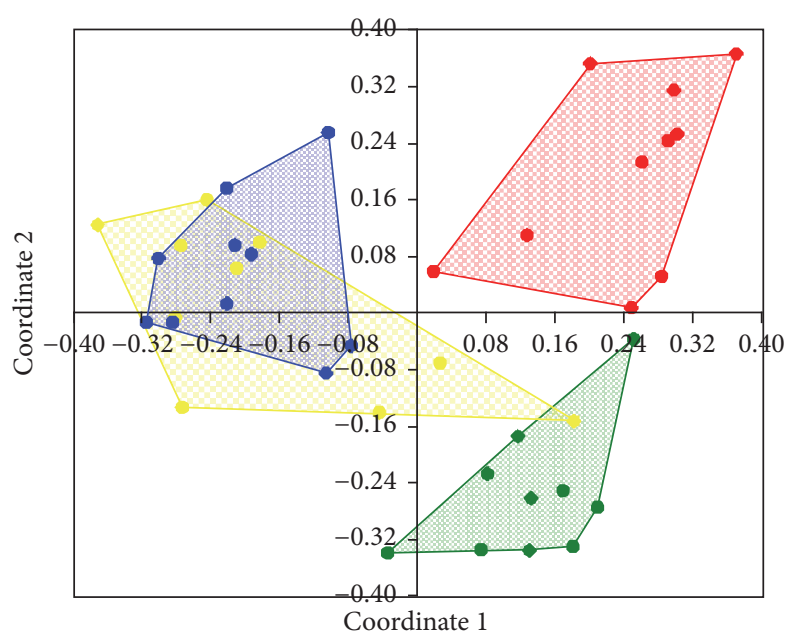

FIgure 5: Principal Coordinates Analysis (PCoA) showing the relationship between the tree species composition and fallows stages in the Cusseque study area (young fallows: green; medium-aged fallows: yellow; old fallows: blue; and mature forests: red).

is clearly separated from all fallow types. The more ample dispersion of the medium fallows in the ordination diagram indicates that they are more heterogeneous in terms of species composition than the other stages. The Analysis of Similarity also showed slight variations in species composition among fallows and mature stands.

The analysis of the Venn diagram found a total of twenty species shared between all categories. Mature stands showed ten unique species and medium fallows showed seven, while two species were found to be unique to old fallows (Figure 6).

3.4. Indicator Species Analysis (ISA). The analysis of indicator species (Table 2) identified 6 indicator species for the mature forest plots. For the fallow stages only a limited number of species were identified as diagnostic. Combretum collinum

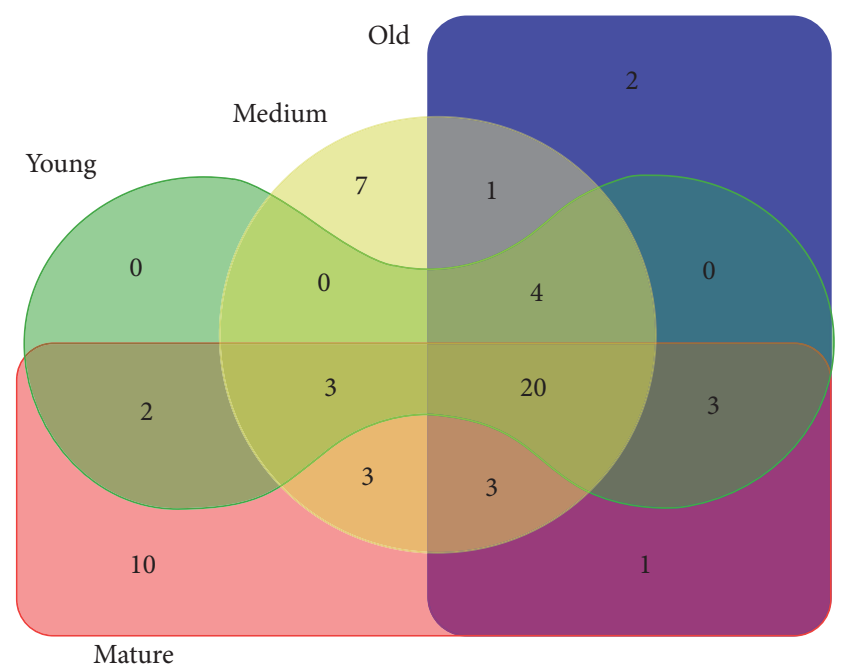

FIgURE 6: Nonsymmetric Venn diagram showing the number of species shared between the forest stages (young fallows: green; medium fallows: yellow; old fallows: blue; and mature forests: red).

and C. zeyheri were indicative of all fallow types. Albizia gummifera was characteristic for young fallows and Pericopsis angolensis for old fallows. The Indicator Species Analysis shows that typical Miombo species rarely were indicative of fallow types, with the exception of Julbernardia paniculata in medium-aged and old fallows.

\section{Discussion}

4.1. Woody Species Diversity. Species diversity is the most commonly used representation of ecological diversity and can be measured from the number of species (species richness) and relative abundance of individuals within each species (species abundance) [58]. We assessed woody species diversity in multiple ways including species richness, which was 
measured from the total number of species occurring in different fallows stages and mature forests. We observed an increase in species richness with fallow age. However, stand age may not necessarily be the most important determinant of floristic composition and even stand structure. Other factors, such as initial floristic composition and land use history, may need to be considered further $[59,60]$. The observed species richness values in the early stage of regrowth are comparable to those of mature stands, while the species composition did not completely recover in the observed time frame and may take several decades to be the same as mature forests [61].

Further diversity measures such as Shannon Diversity and Evenness (Buzas \& Gibson's) were used to assess the diversity of woody species in the study area. The Shannon Diversity Index normally varies from 1.5 to 3.5 , rarely exceeding 4.5 [48]. The overall species diversity values found in our study area are in the range of the values encountered in other studies in Miombo woodlands of south-central Africa, indicating that young regrowth and mature forests had high species diversity, while the intermediate stages had low species diversity [62].

The species diversity values encountered were considerably higher compared to other studies conducted in Miombo woodlands in Tanzania where the values found were $H^{\prime}=1.31$, $H^{\prime}=1.32$, and $H^{\prime}=1.42$ [18] and close to those encountered in Zambian Miombo $\left(H^{\prime}=2.5\right.$ in 20 yrs of fallow and $H^{\prime}=2.6$ in 30 yrs of fallow) [44]. The evenness values found were similar in the intermediate stages, implying that the individuals of different species recorded had relatively similar abundances at both stages. Differences in species richness and diversity of the forests are reported to be dependent upon the amount of rainfall that the area receives annually [46].

The high diversity value found in young fallows is a bit unexpected but can be explained by the high environmental heterogeneity of fallows in early successional stages. Young fallows still host some sprouts from stumps of mature forest species, while strong disturbances (like slash-and-burn agriculture) allow light demanding pioneer species to recruit and establish, thus increasing the number of species [63]. With ongoing succession, some of the original forest remnants are disappearing, in part due to environmental stress and to losing out in light competition with early succession species, which causes a decline in species diversity in the mid succession stages. At the same time, the light demanding pioneer species are already disappearing in mid succession.

Other studies reported similarly that species diversity tended to reach levels close to mature forests relatively quickly after disturbance, by maximizing the coexistence of fast growing pioneers and more competitive canopy species, followed by delayed recovery of woody biomass [59, 64, 65]. However, the disturbance intensity of agricultural use may be too high for fast regeneration dynamics. The reestablishment of mature forest species is a slow process, which demands longer time periods than the chronosequence used in our study.

4.2. Species Composition. We recorded a total of 3157 individuals of 51 tree species in a total area corresponding to 4 ha. The total number of species encountered in our study area is sharply far from that encountered in Zambian Miombo, where a total of 2761 individuals corresponding to 83 species were recorded for mature woodlands [44] and they are in the range of values reported in Tanzania and Zimbabwe $[66,67]$, despite using different plot size. The total number of individuals found in the early stages falls within the range encountered in the Miombo woodlands of Kitulangalo Forest Reserve in Tanzania and in Miombo woodlands of Mozambique, using the same plot size or size thresholds for tree inclusion [68, 69]. Significant differences found regarding stand density between early regrowth stages and mature stands may be explained by the fact that abandoned sites are characterized by a continuous decrease in dominance of early successional and fire resistant species and an increase in the presence of slow-growing tree species commonly associated with mature forest habitats [64]. A reverse J-shaped size class distribution observed in the mature stands may indicate a stable population and good recruitment of late successional species.

The woodlands of Cusseque area are dominated by the typical tree species that characterize Miombo forests all over south-central Africa [70-72]. The sole exception was Isoberlinia angolensis which was surprisingly not found in the area, although it is cited as a common codominant species in many Miombo forests [73-75]. The dominance of the Fabaceae subfamily Caesalpinioideae has also been reported in various studies [76-78].

In general, the forest stands showed high variation in terms of species composition, which may imply that each species has a different ecological importance [79]. Strong environmental changes caused by slash-and-burn agriculture, particularly in terms of soil nutrients and microclimate, are slowly converging to the previous conditions with increase of fallow age and may also influence the changes in species composition.

The dominance of Combretum spp. often characterizes areas with high land use pressure, where the species becomes the fastest growing and most dominant tree in early succession stages [46]. The occurrence of Combretum species after disturbance was also reported in various other studies on early secondary succession of Miombo in south-central Africa [80, 81]. The early stages of regrowth are frequently characterized by a high dominance of fire tolerant genera such as Burkea, Pterocarpus, Pseudolachnostylis, and Terminalia [82] and by light demanding genera such as Albizia, Strychnos, and Uapaca [44]. Kwibisa [60] found Brachystegia spiciformis and Julbernardia paniculata as dominant tree species among the canopy of Zambian Miombo, while the understory was dominated by Combretum spp., Ochna schweinfurthiana, Pseudolachnostylis maprouneifolia, Diplorhynchus condylocarpon, Terminalia spp., and Burkea africana.

Erythrophleum africanum and Pericopsis angolensis were recorded in all stand stages, with the exception of the latter, which is not found in mature forest stands. This can be explained by the fact that these tree species are frequently left standing on fields because of the hardness of their trunks. The few individuals of Guibourtia coleosperma and Pterocarpus angolensis found in the study area can be explained by the importance of these woody species as timber and commercial 
value are associated; both species were referred to as the most exploited woody species in the Angolan part of the Okavango basin, at least in the colonial era [83].

The mature forest plots were dominated by Brachystegia spiciformis, Burkea africana, Cryptosepalum exfoliatum subsp. pseudotaxus, and Monotes africanus. The absence of B. spiciformis in the grass dominated stages of previously farmed areas may be due to the species being fire sensitive [82]. The Miombo species indicators showed low dominance in the early stages of regrowth and increased in dominance with age, with the exception of J. paniculata, which was more dominant in the intermediate stages of fallows than in mature forest stands, reinforcing the assumption that the mature stands in the study areas are characterized by the dominance of C. exfoliatum subsp. pseudotaxus. These findings are also in accordance with the biplot diagram displayed from the Principal Components Analysis.

The dominance of C. exfoliatum subsp. pseudotaxus may also be related to sites which are unsustainable for agriculture, therefore, rarely hit by fire; according to local knowledge these areas are normally used for other activities, such as honey production. The long-term leaching processes caused by high precipitation made some of the soils of mature forests very acidic with the lowest $\mathrm{pH}$ values encountered also in the study area $[84,85]$, which may explain the unsuitability of these areas for agricultural purposes.

The Miombo woodlands demonstrate remarkable capacity to return to mature stages after disturbance [72]. Natural recovery from stumps and resprouts of suppressed saplings could explain the increasing number of species with age, as observed in our study site and also reported in various studies in southern Africa (e.g., Chidumayo, [86]). The demand of land for slash-and-burn agriculture means that much of the newly cropped lands quickly degrades and becomes unsuitable for agriculture. Therefore, efficiency of the agricultural systems needs to be enhanced to improve the longevity of fields and reduce the consumption of forests by slash-and-burn agriculture.

4.3. Principal Coordinates, Similarity, and Indicator Species Analysis. The Principal Coordinates Analysis (PCoA) delimited four different groups. The group formed by the mature stands was consistent with the Analysis of Similarity, and the distinction of this group can be also explained by the dominance of Cryptosepalum exfoliatum subsp. pseudotaxus, as demonstrated by the Indicator Species Analysis. Local site-specific environmental characteristics such as relief, topography, and physicochemical soil properties may play a secondary role, as demonstrated in other studies in the woodlands of southern Africa and savanna biome of South America [87, 88].

\section{Conclusions}

The Cusseque study area is characterized by a high diversity of tree species, with the number of tree individuals and species increasing with fallow age. This trend shows an ongoing recovery process of the mature forest ecosystems after slashand-burn agriculture, as long as the woodlands are not subjected to others disturbances. The recovery process may take several decades to reach mature forests status. Increasing pressure for land demand and other disturbances increasingly become a determining hindrance for forest recovery.

\section{Competing Interests}

The authors declare that there is no conflict of interests regarding the publication of this paper.

\section{Acknowledgments}

The authors are grateful to the Germany Federal Ministry of Education and Research (BMBF) for providing financial support for this study, through the Future Okavango Project (Grant no. 01LL0912A). Special thanks are due to the traditional authorities, local communities in general, and local field guides in Cusseque study area. The authors would like also to acknowledge the staff of ISCED Huíla for all of the support given during the project implementation, the staff at the Herbarium of Lubango, and the working group at Biocentre Klein Flottbek of the University of Hamburg. Special thanks are due to the Remote Sensing Team of the University of Trier for performing the analysis of fallow age using LandTrendr.

\section{References}

[1] C. Sebukeera, E. Muramira, C. Momokama et al., "Forests and woodlands," in Africa Environment Outlook 2 Our Environment, Our Wealth, charpter 6, UNEP, 2006.

[2] J. Clarke, W. Cavendish, and C. Coote, "Rural households and miombo woodlands: use, value and management," in The Miombo in Transition: Woodlands and Welfare in Africa, charpter 5, CIFOR, 1996.

[3] J. M. Bila and N. Mabjaia, "Crescimento e fitossociologia de uma floresta com Colophospermum mopane, em Mabalane, Província de Gaza, Moçambique," Pesquisa Florestal Brasileira, vol. 32, no. 71, pp. 421-427, 2012.

[4] M. L. Du Preez, "Southern Africa's Dryland forest, climate change and the water-energy-food security," Occasional Paper 189, South African Institute of International Affairs. SADC, 2014.

[5] N. N. P. Júnior, R. S. S. Murrieta, and C. Adams, "A agricultura de corte e queima: um sistema em transformação," Boletim do Museu Paraense Emílio Goeldi. Ciências Humanas, vol. 3, no. 2, pp. 153-174, 2008.

[6] K. Pelzer, "Land utilization in the humid tropics," in Proceedings of the 9th Pacific Science Congress, vol. 20, November-December 1957.

[7] E. B. Haney Jr., The Nature of Shifting Cultivation in Latin America, The Land Tenure Center, University of Wisconsin Madison, 1968.

[8] S. Dhakal, "An anthropological perspective on shifting cultivation: a case study of Khoriya cultivation in the Arun Valley of Eastern Nepal," Occasional Papers in Sociology and Anthropology, vol. 6, pp. 93-111, 2000.

[9] T. A. Aththorick, D. Setiadi, Y. Purwanto, and E. Guhardj, "Vegetation stands structure and aboveground biomass after the shifting cultivation practices of Karo People in Leuser 
Ecosystem, North Sumatra," Biodiversitas, Journal of Biological Diversity, vol. 13, no. 2, pp. 92-97, 2012.

[10] T. Karthik, G. G. Veeraswami, and P. K. Samal, "Forest recovery following shifting cultivation: an overview of existing research," Tropical Conservation Science, vol. 2, no. 4, pp. 374-387, 2009.

[11] R. F. Watters, Shifting Cultivation in Latin America, FAO, Rome, Italy, 1971.

[12] L. Christanty, "Shifting cultivation and tropical soils: patterns, problems, and possible improvements," in Traditional Agriculture in Southeast Asia: A Human Ecology Perspective, G. G. Marten, Ed., West View Press, Boulder, Colo, USA, 1968.

[13] J. Neelo, D. Teketay, K. Kashe, and W. Masamba, "Stand structure, diversity and regeneration status of woody species in open and exclosed dry woodlands sites around molapo farming areas of the Okavango Delta, Northeastern Botswana," Open Journal of Forestry, vol. 5, no. 4, pp. 313-328, 2015.

[14] E. Spencer, Shifting Cultivation in Southeast Asia, vol. 19 of University of California Publication in Geography, University of California Press, Berkeley, Calif, USA, 1966.

[15] G. Kowero, B. M. Campbell, and U. R. Sumaila, Policies and Governance Structures in Woodlands of Southern Africa, CIFOR, Bogor, Indonesia, 2003.

[16] R. F. R. Monteiro, Alguns Elementos de Interesse Ecológico da Flora Lenhosa do Planalto do Bié (Angola), Instituto de Investigação Científica de Angola, Luanda, Angola, 1970.

[17] M. E. Durigan, Florística, dinâmica e análise proteíca de uma Floresta Ombrófila Mista em São João do Triunfo-PR [Dissertação de Mestrado em Manejo Florestal], Universidade Federal do Paraná, Curitiba, Brasil, 1999.

[18] J. A. Isango, "Stand structure and tree species composition of Tanzania miombo woodlands: a case study from miombo woodlands of community based forest management in Iringa District," Working Papers of the Finnish Forest Research Institute, no. 50, pp. 43-56, 2007.

[19] M. C. Hansen, P. V. Potapov, R. Moore et al., "High-resolution global maps of 21st-century forest cover change," Science, vol. 342, no. 6160, pp. 850-853, 2013.

[20] A. Gröngröft, J. Luther-Mosebach, L. Landschreiber, R. Revermann, M. Finckh, and A. Eschenbach, "Cusseque-landscape," Biodiversity \& Ecology, vol. 5, pp. 43-44, 2013.

[21] T. Weber, "Cusseque-climate," Biodiversity and Ecology, vol. 5, pp. 45-46, 2013.

[22] M. Finckh, R. Revermann, and M. P. M. Aidar, "Climate refugees going underground-a response to Maurin et al. (2014)," New Phytologist, vol. 209, no. 3, pp. 904-909, 2016.

[23] R. Revermann and M. Finckh, "Okavango basin-vegetation," Biodiversity \& Ecology, vol. 5, pp. 29-35, 2013.

[24] H. K. A. Shaw, "The vegetation of Angola," Journal of Ecology, vol. 35, no. 1-2, pp. 23-48, 1947.

[25] L. A. G. Barbosa, Carta Fitogeográfica de Angola, Instituto de Investigação Científica de Angola, Luanda, Angola, 1970.

[26] C. A. Diniz, Características Mesológicas de Angola: Descrição e Correlação dos Aspecto Fisiográficos dos Solos e da Vegetação da Zonas Agrícolas Angolanas, Missão de Inquéritos Agrícolas de Angola, Nova Lisboa, Angola, 1973.

[27] B. J. Huntley and E. M. Matos, "Botanical diversity and its conservation in Angola," in Botanical Diversity in Southern Africa. Strelitzia 1, B. J. Huntley, Ed., pp. 53-74, National Botanical Institute, Pretoria, South Africa, 1994.

[28] R. Revermann, F. Maiato, A. Gomes, F. Lages, and M. Finckh, “Cusseque-Vegetation," Biodiversity \& Ecology, vol. 5, pp. 59-63, 2013.
[29] M. Stellmes, D. Frantz, M. Finckh, and R. Revermann, “Okavango basin-earth observation," Biodiversity \& Ecology, vol. 5, pp. 23-27, 2013.

[30] S. Domptail, L. M. Große, B. Kolwalski, and J. Baptista, "Cusseque/Cacuchi-The People," Biodiversity \& Ecology, vol. 5, pp. 73-80, 2013.

[31] J. Wehberg and T. Weinzierl, "Okavango Basin-physicogeographical setting," Biodiversity \& Ecology, vol. 5, pp. 11-13, 2013.

[32] R. E. Kennedy, Z. Yang, and W. B. Cohen, "Detecting trends in forest disturbance and recovery using yearly Landsat time series: 1. LandTrendr-temporal segmentation algorithms," Remote Sensing of Environment, vol. 114, no. 12, pp. 2897-2910, 2010.

[33] J. M. Felfili, F. A. Carvalho, and R. F. Haidar, Manual para Monitoramento de Parcelas Permanentes nos Biomas de Cerrado e Pantanal, Universidade de Brasília, Brasília, Brazil, 2005.

[34] E. Figueiredo and G. Smith, Plants of Angola/Plantas de Angola, Strelitzia 22, South African National Biodiversity Institute, Pretoria, South Africa, 2008.

[35] M. Begon, C. R. Townsend, and J. Harper, ECOLOGY from Individuals to Ecossystems, Blackwell Publishing, 4th edition, 2006.

[36] A. E. Magurran, "Measuring biological diversity," Journal of the Torrey Botanical Society, vol. 131, no. 3, pp. 277-278, 2004.

[37] C. H. R. Heip, P. M. J. Herman, and K. Soetaert, "Indices of diversity and evenness," Oceanis, vol. 24, no. 4, pp. 61-87, 1998.

[38] M. R. Kanieski, A. C. B. Araújo, and S. J. Longhi, "Diversity quantification in Mixed Ombrophilous Forest by different Alpha Indexes," Scientia Forestalis, vol. 38, no. 88, pp. 567-577, 2010.

[39] T. Leinster and C. A. Cobbold, "Measuring diversity: the importance of species similarity," Ecology, vol. 93, no. 3, pp. 477489, 2012.

[40] M. L. Carranza, A. Acosta, and C. Ricotta, "Analyzing landscape diversity in time: the use of Rènyi's generalized entropy function," Ecological Indicators, vol. 7, no. 3, pp. 505-510, 2007.

[41] J. Oldeland, N. Dreber, and D. Weduls, "Diversity measures in comparative rangeland studies: application and advantages of species abundance distributions and diversity profiles," Dinteria, no. 31, pp. 50-66, 2010.

[42] Ø. Hammer, PAST: Paleontological Statistics. Version 2.17: Reference Manual, Natural History Museum, University of Oslo, 2012.

[43] J. T. Curtis and R. P. McIntosh, "An upland forest continuum in the Prairie-forest border region of Wisconsin," Ecology, vol. 32, no. 3, pp. 476-496, 1951.

[44] F. K. Kalaba, C. H. Quinn, A. J. Dougill, and R. Vinya, "Floristic composition, species diversity and carbon storage in charcoal and agriculture fallows and management implications in Miombo woodlands of Zambia," Forest Ecology and Management, vol. 304, pp. 99-109, 2013.

[45] P. K. T. Munishi, R. A. P. C. Temu, and G. Soka, "Plant communities and tree species associations in Miombo ecosystems in Lake Rukwa basin, Southern Tanzania: Implications for conservation," Journal of Ecology and the Natural Environment, vol. 3, no. 2, pp. 63-71, 2011.

[46] E. K. K. Jew, A. J. Dougill, S. M. Sallu, J. O’Connell, and T. G. Benton, "Miombo woodland under threat: consequences for tree diversity and carbon storage," Forest Ecology and Management, vol. 361, pp. 144-153, 2016. 
[47] D. Mueller-Dumbois and H. Ellenberg, Aims \& Methods of Vegetation Ecology, John Wiley \& Sons, New York, NY, USA, 1974.

[48] M. Kent and P. Coker, Vegetation Description and Analysis: A Practical Approach, John Wiley \& Sons, 1992.

[49] W. K. Freitas and L. M. S. Magalhães, "Métodos e Parâmetros para Estudo da Vegetação com Ênfase no Estrato Arbóreo," Floresta e Ambiente, no. 19, pp. 520-540, 2012.

[50] K. R. Gabriel, "The biplot graphic display of matrices with application to principal component analysis," Biometrika, vol. 58, no. 3, pp. 453-467, 1971.

[51] F. Udina, "Interactive biplot construction," Journal of Statistical Software, vol. 13, no. 5, pp. 1-16, 2005.

[52] J. W. Huntley, "Charpter 2: exploratory multivariate techniques and their utility for understanding ancient ecosystems," in Quantifying the Evolution of Early Life, M. Laflamme, J. D. Schiffbauer, and S. Q. Dornbos, Eds., vol. 36 of Topics in Geobiology, pp. 23-48, Springer, Dordrecht, Netherlands, 2011.

[53] K. R. Clarke and R. M. Warwick, Change in Marine Communities: An Approach to Statistical Analysis and Interpretation, PRIMER-E, Plymouth, UK, 2nd edition, 2001.

[54] B. McCune, J. B. Grace, and D. L. Urban, Analysis of Ecological Communities, MjM Software Design, Gleneden Beach, Ore, USA, 2002.

[55] R Development Core Team, R: A Language and Environment for Statistical Computing, R Foundation for Statistical Computing, Vienna, Austria, 2015.

[56] M. De Cáceres, P. Legendre, and M. Moretti, "Improving indicator species analysis by combining groups of sites," Oikos, vol. 119, no. 10, pp. 1674-1684, 2010.

[57] M. Dufrêne and P. Legendre, "Species assemblages and indicator species: the need for a flexible asymmetrical approach," Ecological Monographs, vol. 67, no. 3, pp. 345-366, 1997.

[58] A. J. Hamilton, "Species diversity or biodiversity?" Journal of Environmental Management, vol. 75, no. 1, pp. 89-92, 2005.

[59] C. Uhl, "Factors controlling succession following slash-andburn agriculture in Amazonia," Journal of Ecology, vol. 75, no. 2, pp. 377-407, 1987.

[60] L. Kwibisa, The effects of indigenous cultivation practices on the recovery of dry Miombo woodland in Central Zambia [M.S. thesis], University of Zambia, 2000.

[61] J. K. K. N'Dja and G. Decocq, "Successional patterns of plant species and community diversity in a semi-deciduous tropical forest under shifting cultivation," Journal of Vegetation Science, vol. 19, no. 6, pp. 809-820, 2008.

[62] F. C. Lumbwe, Modeling avifauna responses to Miombo woodland degradation in Serenje District, central province, Zambia [Ph.D. thesis], University of Zambia, 2010.

[63] T. Banda, M. W. Schwartz, and T. Caro, "Woody vegetation structure and composition along a protection gradient in a miombo ecosystem of western Tanzania," Forest Ecology and Management, vol. 230, no. 1-3, pp. 179-185, 2006.

[64] I. M. McNicol, C. M. Ryan, and M. Williams, "How resilient are African woodlands to disturbance from shifting cultivation?" Ecological Applications, vol. 25, no. 8, pp. 2330-2336, 2015.

[65] T. H. Mwampamba and M. W. Schwartz, "The effects of cultivation history on forest recovery in fallows in the Eastern Arc Mountain, Tanzania," Forest Ecology and Management, vol. 261, no. 6, pp. 1042-1052, 2011.

[66] C. J. Mafupa, Impact of human disturbances in Miombo Woodlands of Igombe River Forest Reserve, Nzega District, Tanzania
[M.S. thesis], Sokoine University of Agriculture, Morogoro, Tanzania, 2006.

[67] P. Gandiwa, E. Chinoitezvi, and E. Gandiwa, "Structure and composition of woody vegetation in two important bird areas in southern Zimbabwe," Journal of Animal \& Plant Sciences, vol. 23, no. 3, pp. 813-820, 2013.

[68] L. Mbwambo, S. Valkonen, and V. Kuutti, "Structure and dynamics of miombo woodland stands at Kitulangalo Forest Reserve," Working Papers of the Finnish Forest Research Institute, vol. 98, pp. 10-19, 2008.

[69] N. S. Ribeiro, C. N. Matos, I. R. Moura, R. A. WashingtonAllen, and A. I. Ribeiro, "Monitoring vegetation dynamics and carbon stock density in miombo woodlands," Carbon Balance and Management, vol. 8, article 11, 2013.

[70] J. O. Oyugi, J. S. Brown, and C. J. Whelan, "Effects of human disturbance on composition and structure of Brachystegia woodland in Arabuko-Sokoke Forest, Kenya," African Journal of Ecology, vol. 46, no. 3, pp. 374-383, 2007.

[71] I. M. Grundy, B. M. Campbell, and P. G. H. Frost, "Spatial pattern, regeneration and growth rates of Brachystegia spiciformis and Julbernardia globiflora," Vegetatio, vol. 115, no. 2, pp. 101-107, 1994.

[72] D. D. Shirima, O. Totland, P. K. T. Munishi, and S. R. Moe, “Does the abundance of dominant trees affect diversity of a widespread tropical woodland ecosystem in Tanzania?" Journal of Tropical Ecology, vol. 31, no. 4, pp. 345-359, 2015.

[73] E. N. Chidumayo, "Species structure in Zambian miombo woodland," Journal of Tropical Ecology, vol. 3, no. 2, pp. 109-118, 1987.

[74] P. V. Desanker and I. C. Prentice, "MIOMBO—a vegetation dynamics model for the miombo woodlands on Zambezian Africa," Forest Ecology and Management, vol. 69, no. 1-3, pp. 8795, 1994.

[75] F. White, The Vegetation of Africa, A Descriptive Memoir to Accompany the UNESCO/AETFAT/UNSO Vegetation Map of Africa, vol. 20 of Natural Resources Research, UNESCO, Paris, France, 1983.

[76] E. J. Francisco, C. G. Africano, M. Sanfilippo, Y. G. Quintana, I. C. Martinez, and Y. A. Crespo, "Estructura y composición del bosque Miombo del Sector Norte de Canjombe, Angola," Revista Forestal Baracoa, vol. 33, pp. 306-316, 2014.

[77] N. Muboko, M. R. Mushonga, N. Chibwe, C. Mashapa, and E. Gandiwa, "Woody vegetation structure and composition in Mapembe Nature Reserve Eastern Zimbabwe," Journal of Applied Sciences and Environmental Management, vol. 17, no. 4, pp. 475-481, 2013.

[78] E. E. Mwakalukwa, H. Meilby, and T. Treue, "Floristic composition, structure and species associations of dry Miombo Woodland in Tanzania," International Journal of Forestry Research, vol. 2014, Article ID 153278, 15 pages, 2014.

[79] H. A. Wale, T. Bekele, and G. Dalle, "Floristic diversity, regeneration status, and vegetation structure of woodlands in Metema Area, Amhara National Regional State, Northwestern Ethiopia," Journal of Forestry Research, vol. 23, no. 3, pp. 391-398, 2012.

[80] P. Stromgaard, "Early secondary succession on abandoned shifting cultivator's plots in the Miombo of South Central Africa," Biotropica, vol. 18, no. 2, pp. 97-108, 1986.

[81] I. Backéus, B. Pettersson, L. Strömquist, and C. Ruffo, “Tree communities and structural dynamics in miombo (BrachystegiaJulbernardia) woodland, Tanzania," Forest Ecology and Management, vol. 230, no. 1-3, pp. 171-178, 2006. 
[82] T. R. McClanahan and T. P. Young, Eds., East African Ecosystems and their Conservation, Oxford University Press, New York, NY, USA, 1996.

[83] N. Baptista, "Literature study of the woody Miombo vegetation and forest management in southeastern Angola with focus on data from the colonial era," Polytechnic of Namibia in framework of The Future Okavango Project SP05-Task 6, 2014.

[84] E. N. Chidumayo, "Using natural fertilizers in Miombo woodlands," Issues in African Biodiversity-The Biodiversity Support Program, no. 2, pp. 1-8, 1999.

[85] A. Gröngröft, "Cusseque-soils," Biodiversity and Ecology, vol. 5, pp. 51-54, 2013.

[86] E. N. Chidumayo, "Development of Brachystegia-Julbernardia woodland after clear-felling in central Zambia: evidence for high resilience," Applied Vegetation Science, vol. 7, no. 2, pp. 237242, 2004.

[87] S. Syampungani, Vegetation change analysis and ecological recovery of the Copperbelt Miombo woodlands of Zambia [Ph.D. thesis], Stellenbosch University, Stellenbosch, South Africa, 2009.

[88] E. Lenza, J. O. Santos, and L. Maracahipes-Santos, "Species composition, diversity, and vegetation structure in a gallery forest-cerrado sensu stricto transition zone in eastern Mato Grosso, Brazil," Acta Botanica Brasilica, vol. 29, no. 3, pp. 327$338,2015$. 

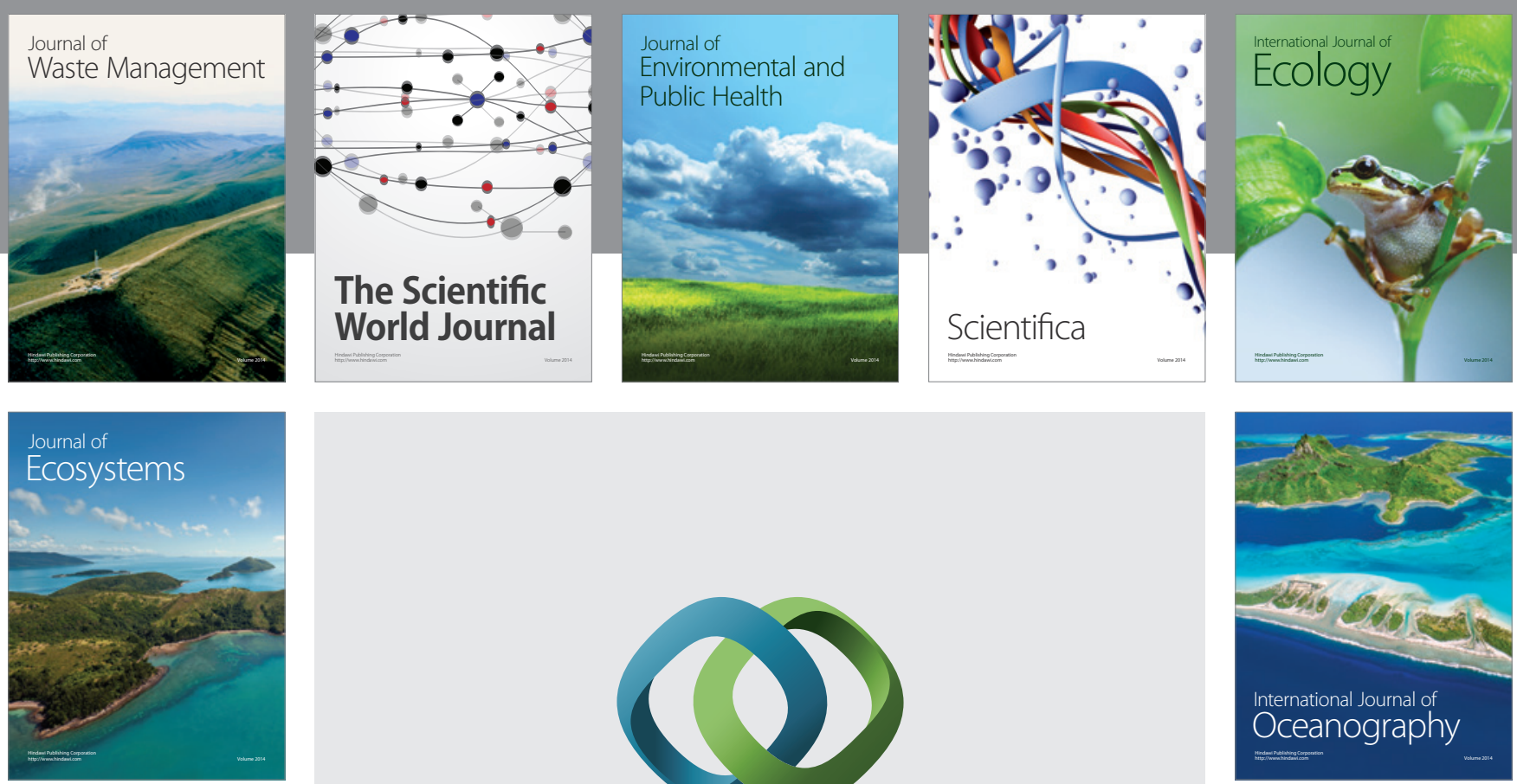

The Scientific World Journal
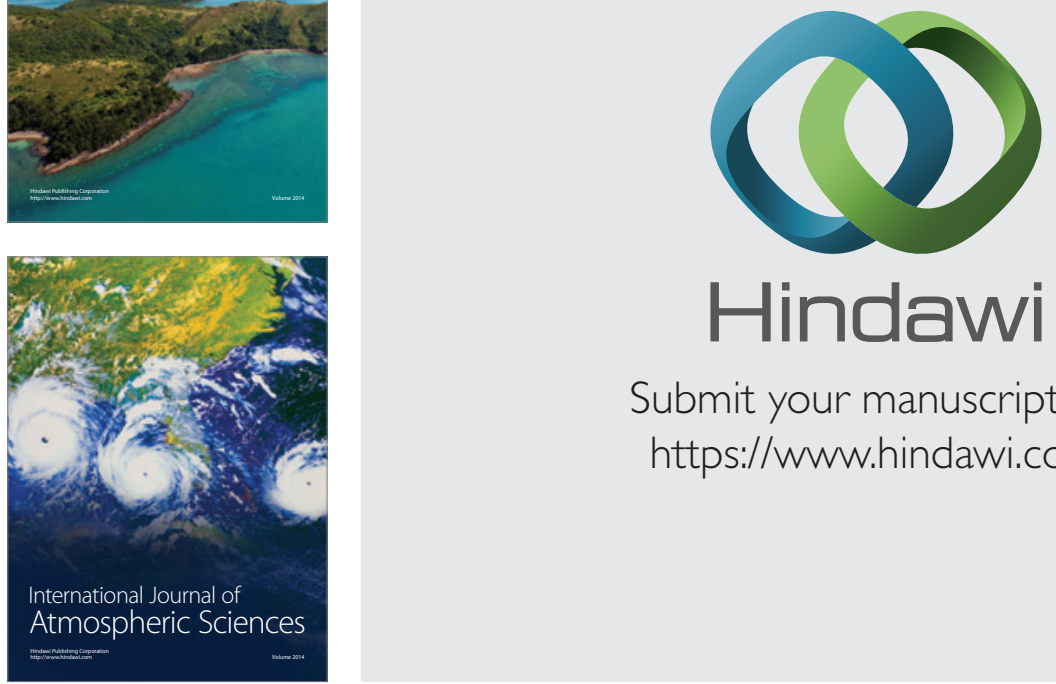

Submit your manuscripts at

https://www.hindawi.com
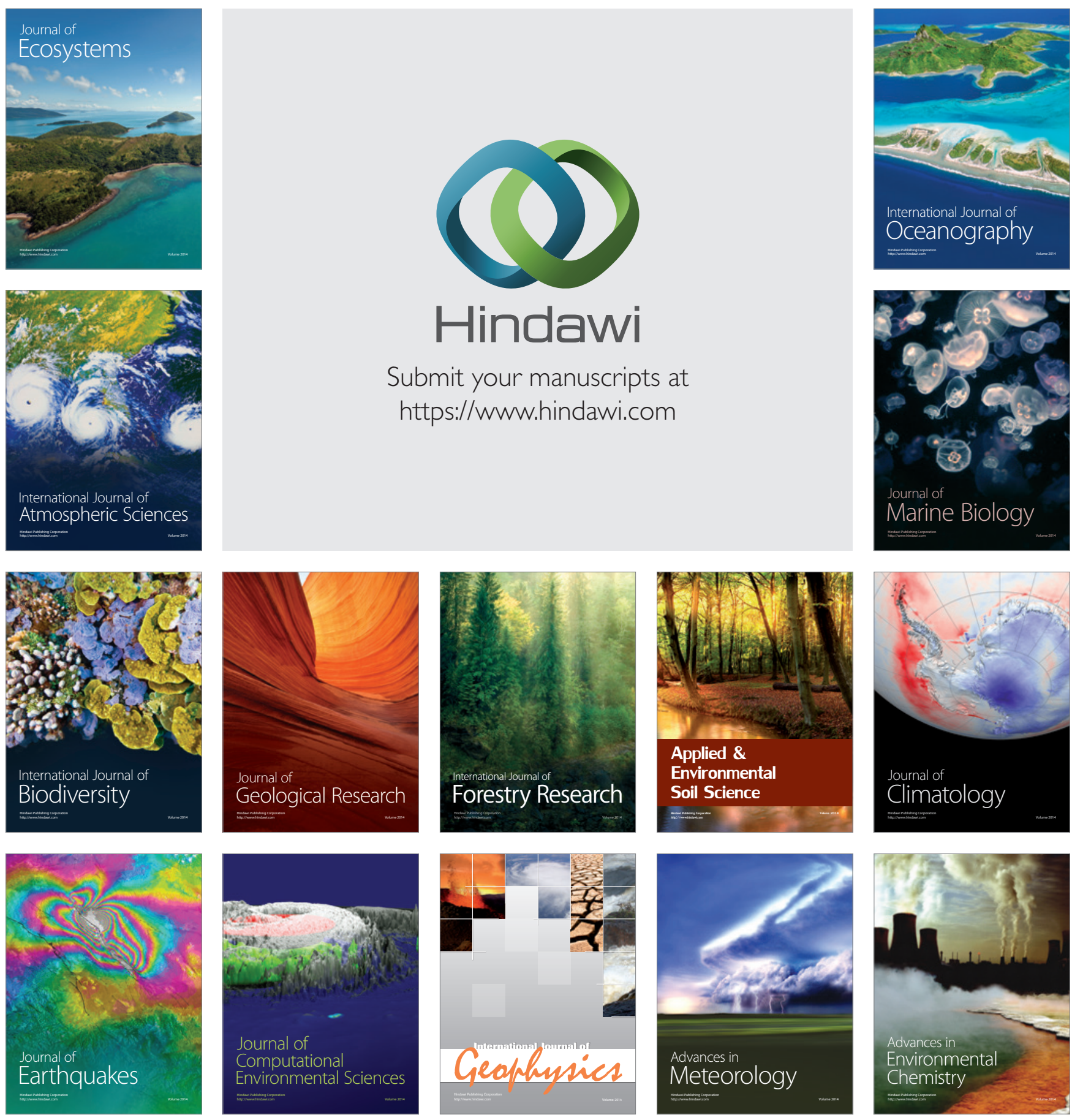